\title{
Anabases
}

ANABASES Traditions et réceptions de l'Antiquité

25 | 2017

Varia

\section{Federico SANTANGELO, Marius}

\section{Cyrielle Landrea}

\section{OpenEdition \\ Journals}

Édition électronique

URL : http://journals.openedition.org/anabases/6155

DOI : 10.4000/anabases.6155

ISSN : 2256-9421

\section{Éditeur}

E.R.A.S.M.E.

\section{Édition imprimée}

Date de publication : 1 avril 2017

Pagination : 301-302

ISSN : 1774-4296

\section{Référence électronique}

Cyrielle Landrea, « Federico santangelo, Marius », Anabases [En ligne], 25 | 2017, mis en ligne le 01 avril 2017, consulté le 20 janvier 2021. URL : http://journals.openedition.org/anabases/6155 ; DOI : https:// doi.org/10.4000/anabases.6155

Ce document a été généré automatiquement le 20 janvier 2021.

(c) Anabases 


\title{
Federico SANTANGELO, Marius
}

\author{
Cyrielle Landrea
}

\section{RÉFÉRENCE}

Federico SANTANGELo, Marius

Londres, Bloomsbury Academic, 2016,

124 p., 16.99 livres / ISBN 978474214711

1 La collection Ancients in Action a un double but : offrir de courtes biographies sur des figures essentielles de l'Histoire ancienne et en analyser la réception dans la civilisation occidentale. L'ouvrage est confié à un grand spécialiste de l'époque tardorépublicaine : F. Santangelo, Marius est un ouvrage destiné au grand public et aux étudiants. Cela se ressent fortement dans la conception même du livre (sans note et sans longue bibliographie) ; des " instruments de travail " sont aussi inclus, comme une chronologie (p. IX-XI), une carte de l'Italie (p. XII) et un stemma de la famille de Marius (p. 13).

2 Selon F. Santangelo, l'historiographie a négligé depuis une cinquantaine d'années les " grands hommes » au profit notamment d'études diachroniques ou d'autres consacrées à des groupes sociaux précis. Il ne s'agit pas seulement d'écrire une courte biographie sur Marius, mais d'analyser à court terme les ruptures induites par sa carrière exceptionnelle avant d'en mesurer l'impact sur le temps long. Dans cette perspective, le plan choisi permet de retracer facilement et efficacement la carrière de cet imperator : une phase introductive, l'ascension de l'homo nouus avant sa chute, les revers de fortune et l'héritage marianiste.

3 L'introduction est l'occasion d'un bref rappel historiographique dans une perspective très large : de Machiavel à Mommsen. Selon l'auteur de la Renaissance, Marius était déjà considéré comme une des principales causes de la chute de la République. Au-delà de cet héritage historiographique, F. Santangelo revient sur les origines de cet homo nouus et sur des éléments clés de la tradition. L'entreprise biographique aura alors pour but de sortir du portrait dressé par cette tradition biaisée. C'est pourquoi l'auteur 
invite justement à la prudence dans l'utilisation des sources. Il serait en effet imprudent de dresser un portrait personnel de Marius ou de déterminer son caractère à l'aune de sources partiales, littéraires ou simplement postérieures. Par exemple le refus d'apprendre le grec selon Plutarque ne tient pas lorsqu'on s'intéresse à la politique orientale de l'imperator.

4 La carrière de Marius ne peut pas se comprendre ex nihilo, c'est-à-dire sans mesurer le contexte particulier de la fin de la République. Le titre du chapitre 2 (Marius' rise) est limpide et couvre une période vaste, allant du début de la carrière à la victoire sur les Cimbres et les Teutons. Tous les moments de gloire sont ainsi passés en revue, comme la guerre contre Jugurtha (p. 25-41). F. Santangelo note d'ailleurs à propos de cette dernière qu'il s'agit d'un événement mineur dans l'histoire de l'impérialisme romain, mais qui connut pourtant une grande postérité grâce à Salluste. La candidature au consulat apparaît forcément comme une rupture ; c'est un élément fort bien connu. C'est pourquoi l'auteur s'intéresse davantage aux processus et aux buts des grands commandements militaires de Marius. Tout ceci est ainsi fort bien détaillé et $\mathrm{F}$. Santangelo invite à ne pas surestimer la réforme militaire. La lutte contre les Germains est ensuite largement développée (p. 41-56) et elle est alors considérée comme l'acmé de sa carrière. Les références géographiques sont précises (p.53) et intègrent notamment les différentes localisations de Vercellae. Toutefois la carte (p. XII) ne retient qu'une localisation au Nord-Ouest de l'Italie.

Le plus succinct chapitre 3 est consacré à la chute de Marius (p. 57-70). Comme souvent, l'auteur invite à la prudence et à ne pas surestimer la candidature de $100 \mathrm{au}$ consulat. Il ne s'agirait pas seulement d'une manifestation d'ambition démesurée. Elle est effectivement avant tout à replacer dans un contexte politique très tendu où de nombreux protagonistes trouvent la mort. Ce climat délétère est bien évidemment au cœur du chapitre 4 (Twists of Fate, p. 71-94) avec la guerre sociale et la guerre civile entre marianistes et syllaniens. La fuite en Afrique est notamment abordée, y compris sous l'angle de la réception artistique (p. 86).

Le dernier chapitre (Marius' Legacy, p. 95-103) s'écarte de la simple biographie. La postérité marianiste est vue à plusieurs niveaux : celui des marianistes (y compris du fils de Marius) et celui de la résurgence de sa memoria à l'époque de César ; sans oublier une analyse plus originale sur la postérité de Marius sous le Principat où il devient alors une simple grande figure du passé utilisée par Auguste.

7 Pour conclure, ce petit ouvrage n'a pas pour vocation d'être une énième biographie soidisant exhaustive, mais d'être une première introduction destinée aux étudiants. Le contrat est de ce point de vue pleinement rempli. Le récit est précis et la chronologie est bien détaillée. F. Santangelo n'est pas catégorique ; c'est pourquoi les hypothèses sont présentées comme telles et non doctement imposées comme des vérités. Toutefois Marius n'est pas exempt de quelques défauts dus à la collection. En effet, l'auteur cite les auteurs sans donner les passages précis, comme le souhaite la collection Ancients in Action. Pour pallier cette difficulté, le lecteur trouvera à la fin de l'ouvrage une liste de références thématiques aux sources antiques. Ce compromis n'est pas pratique et il aurait été largement souhaitable de donner les sources directement dans le corps du texte. 


\section{AUTEURS}

CYRIELLE LANDREA

Laboratoire ANHIMA UMR 8210

cyrielle.landrea@orange.fr 